Memarnia, N., Nolte, L., Norris, C. \& Harborne, A. (2015) 'It felt like it was night all the time': listening to the experiences of birth mothers whose children have been taken into care or adopted, Adoption and Fostering, 39(4): 303-317.

\title{
'It felt like it was night all the time': Listening to the experiences of birth mothers whose children have been taken into care or adopted
}

\begin{abstract}
The literature consistently reports a lack of support for birth mothers following their child being taken into care or adopted (Logan, 1996; Schofield, 2009; Schofield, 2010). This is despite consistent evidence of the longterm consequences that the removal of children has upon their mental health (Condon, 1986; Wells, 1993; Logan, 1996). O'Leary-Wiley \& Baden (2005) write, 'Birth parents are the least studied, understood, and served members of the adoption triad.' The aim of the study was to explore: the experience of separation, sense of identity following separation, experience of contact and experience of support through the process. Semistructured interviews were conducted with seven mothers who were recruited from birth mother support groups. The transcripts of the interviews were analysed using Interpretative Phenomenological Analysis (IPA). Four main themes emerged across the participants' accounts: 'No one in my corner', 'Disconnecting from emotion', 'Renegotiating identity' and 'The children are gone, but still here'. The findings contribute to our understanding of the experiences of birth mothers and are discussed within a range of psychological theories. Implications for clinical psychology are considered.
\end{abstract}

\section{Introduction}

The present study seeks to explore the experiences of birth mothers whose child or children have been taken into care or adopted. The British Association for Adoption and Fostering report that 67,050 children were in the care of local authorities in 2012. In the same year, 3,450 children were adopted. The Adoption and Children Act 2002 (Sections 3 \& 4) in England and Wales, and the Adoption and Children Act 2007 (Sections 3-5) in Scotland stress the importance of providing independent support both during and after the adoption process. The National Minimum Standards for adoption that accompany the Act state that:

Birth parents and birth families.... are entitled to services that recognise the lifelong implications of adoption. They will be treated fairly, openly and with respect throughout the adoption process

(Department of Health, 2001, p. 23)

Despite recognition of the needs of birth parents, they remain a largely neglected group on practice, research and policy. Zamostny, O'Leary-Wiley, O'Brien, Lee, \& Baden (2003) write:

'The silence of the mental health community on and psychology's relative lack of research attention to adoption issues compromise empirically based knowledge on adoption.' (p.648)

The authors go on to assert that psychologists' expertise in clinical interventions and research methodology could be used to advance our knowledge of psychological adjustment to adoption. However, psychologists' lack of attention to this area has meant that it had not benefitted from such contributions, even though they have much to offer.

Very little research has been undertaken which looks specifically at birth mothers' experience of being compulsorily separated from their children, particularly research in the UK. In addition, 
much of the research undertaken has been done so with birth mothers who have relinquished their children voluntarily. While in many ways this is a comparable experience, it does not speak to the uniqueness of having one's child or children compulsorily removed.

A number of studies suggest that the removal of children has long term consequences for the mental health of birthmothers (Winkler \& Van Keppel, 1984; Condon, 1986; Wells, 1993; Logan, 1996; Scholfield et al, 2011; Neil, 2013). Winkler \& Van Keppel (1984) found that birth mothers' sense of loss intensified over time and six of the women also became pregnant again within a year of relinquishment, which is a trend still evident today and a growing national concern.

The birth mother task of psychological adjustment to loss is impeded by the denial of the importance of the loss by other people as well as the woman's own sense of guilt and shame (Howe, Sawbridge \& Hinings, 1992; Logan, 1996; Milham Bullock, Hosie \& Haak, 1986; Neil, 2004; Aloi, 2009). These studies relate this to the concept of 'disenfranchised grief', defined by Doka (1989) as 'grief that is not openly acknowledged, socially accepted or publicly mourned'.

A range of theoretical frameworks have been used in the literature to discuss the experiences of birth mothers. Grief and loss appear to be the most common (Henney, Ayers-Lopez, McRoy, \& Grotevant, 2007; Robinson, 2002) and some studies make reference to trauma (Castle, 2010; O'Leary-Wiley \& Baden, 2005, Charlton et al, 1998) and Post Traumatic Stress Disorder (PTSD) (Wells, 1993).

The literature consistently reports a lack of support for birth mothers following their child being taken into care (Logan, 1996; Charlton et al, 1998; Schofield et al, 2009; Schofield et al, 2010). Charlton et al (1998) has suggested that this is a consequence of the societal attitudes towards mothers whose children have been taken into care. In addition to this, birth parents often find it difficult to access services that are available due to feelings of anger at the agencies involved in the removal of their child. Cossar \& Neil (2010, p. 1371) write: 'It is often difficult to engage birth mothers who have complex needs and who are disempowered and distrusting of professionals'. Sellick (2007) suggests that support services should be perceived as independent, be available at different points in the adoption process and be delivered by practitioners who are informed about adoption issues. In a survey to map the provision of adoption support services and contact support services in England and Wales, it was found that whilst every local authority provided some birth relative support service, there was a wide variation in what this support looked like. Support for contact was the most common service to be provided, with advocacy and therapy the least common (Sellick, 2007). Cossar \& Neil (2010) emphasise the importance of support services for birth mothers not only for their own welfare but for the welfare of the child and particularly because contact with the child in care is now commonplace. Provision of support services, therefore, may increase the likelihood of birth mothers being able to sustain contact and the likelihood of this contact being of good quality.

While it has been suggested that contact with one's child leads to better adjustment to the loss, many studies have also suggested that contact arouses painful feelings for birth mothers that are difficult to manage (Logan, 1999; Neil, 2003, 2010, Castle, 2010). Logan (1999) interviewed birth mothers about their experiences of simply receiving information about their child and found that all described both as something they looked forward to and something that was very upsetting. Castle (2010) suggests that, in one way, contact provides a 'solution' to the grief of birth mothers and in another way it leaves the grief 'unresolved'.

The process of taking a child into care through a care order is often a long, gruelling and distressing process. Many have written of the 'adversarial nature' of the child protection process (Ryburn, 1994; Cleaver \& Freeman, 1995; Mason \& Selman, 1997; Drumbill, 2006; Ghaffar, Manby \& Race, 2011; Smeeton \& Boxall, 2011). Court reports are deficit-saturated and are often a source 
of trauma, shame and frustration for the birth parents who are 'publicly branded as bad parents' (Mason \& Selman, 1997; p. 24).

In order to effectively support birth mothers of adopted children or children in care, it is important to understand more fully their needs and experiences, particularly in relation to their emotional well-being. This is also important because it is now common for adopted children to continue to have contact with their birth parents after adoption. As such the emotional well-being of the birth parent will continue to have some bearing on the welfare of the child (Neil, 2013; Neil \& Howe, 2004).

\section{Methodology}

The sample in the current study consisted of seven mothers who were all recruited from birth mother support groups, across two non-NHS organisations. Six of the seven participants described themselves as white British and one described herself as Asian. The majority of participants were between 29 and 35 years old, with one participant being slightly younger at 23 years of age. The length of time that had elapsed since having their children taken into care and/or adopted ranged from 2 years to 9 years. The number of children they had who were in foster care or adopted ranged from 1 to 6 . Three of the mothers interviewed had children living at home with them. All of the mothers continued to have either direct contact or letter-box contact with some or all of their children.

Semi-structured interviews were audio-recorded and transcribed by the researcher. The transcripts were analysed using Interpretative Phenomenological Analysis.

\section{Findings}

\section{No one in my corner}

This theme captures the feeling of all the participants that they were trying to cope alone both before and after their children were taken into care. All participants talked about their children being taken into care in the context of trying to parent alone amidst a chaotic situation at home. Many of the participants felt that there was a lack of support to help them to improve their situation so that the children were not taken into care, leading to feelings of anger towards social services. During the court process, many participants describe feeling that professionals were not hearing their side of the story and that the evidence presented gave the wrong impression of them as parents. All participants conveyed a sense of not feeling important and that their emotions about having their children taken into care were not considered important to professionals.

Tracey described chaotic circumstances and alluded to feeling out of control of her situation:

“My house was like Piccadilly Circus."(Tracey)

Alice did not feel that she was supported to improve her situation so that her child was not taken into care. She also felt that she was left to cope alone afterwards:

"They could've helped with some sort of counselling or whatever for the drinking and obviously I was going through the violent relationship, but they just didn't wanna.... They didn't care, they didn't wanna help. To me it felt like it was just about getting him into care, they didn't care, sort of, how that impacted on me or anything" (Alice) 
Lucy expressed what appeared to be frustration at being unable to get her story across to others. She refers to the power held by professionals which privileges the story that they told about her as a parent and left her in a position of powerlessness:

"... You're in this room, these people have got so much power, and they can ruin your life like that [clicked fingers]. In a snap. On basically listening to other people's evidence, which really is a snapshot of your life because they don't know you, these people." (Lucy)

Lucy's words reflect one of the sub-themes 'One story obscuring other stories' which speaks to the picture painted by participants of feeling powerless in the face of evidence which was stacked up against them and which created a narrative of them as 'bad parents'. The mothers expressed a wish for other stories about them as parents to be told and valued the opportunity to tell their story as part of this study. In summary, the super-ordinate theme 'No one in my corner' represents the mothers' sense of 'going it alone' before, during and after their children being taken into care. This manifests itself both in the lack of support offered to them, their sense of not being considered to be a person with needs and feelings, and in their sense that no one was able to or willing to hear their story as a whole.

\section{Disconnecting from emotion}

All of the participants spoke about their experiences in a way which lacked a sense of connection with the emotional content. This theme captures the ways in which this manifested itself in the mothers' accounts. Some participants used words which described an emotional experience but did so in a matter-of-fact tone. Other participants struggled to find language to describe their emotional experience or to remember how they felt at the time. One of the ways in which it seemed participants were enabled to disconnect from emotion was through a minimisation of the reasons why their child was taken into care.

Lucy poignantly expresses her guilt at having let her children down, suggesting her attempts to minimise the reasons for her children being taken served to protect her from these difficult feelings:

"It's a lot of guilt. You feel so guilty. I mean that's my biggest hurdle, is getting over that. That guilt that I feel that... I messed up. I really messed up, I let them down because ultimately, you're their parent, you're the one that's meant to be there to protect them and make sure these things don't happen and obviously I did." (Lucy)

I asked Sarah to tell me about why her children were removed and she responded with a rather stark description of the reasons which seemed incongruent with the seriousness of what she was telling me:

"Erm, it was mostly missing appointments for her health, not looking after her, making sure she weren't... she was going to school clean... physically neglecting her and mentally, and, that was it." (Sarah)

Many of the participants alluded to their emotional experience following their children being taken as difficult to bear. All participants described coping with the loss through strategies that blocked out their feelings, such as drinking. For many of the participants there was a wish to not show emotion to others, including to myself. There was often a contrast between the way that participants described their internal world, for those who could do this, and how they described what they showed to others. 
Tracey describes being in a state of despair after her children were taken into care and her perceived inability to cope with her feelings:

“... At the beginning I lost the plot, I was self-harming, I was over-dosing, couldn't cope with it all..." (Tracey)

She went on to describe, poignantly, the intensity of her emotions after her children were taken and her attempts to escape from them:

“... I locked myself away. Locked myself in my bedroom basically and just played Xbox or computer ... and that's all I did... It felt like I'd never be happy again. It felt like it was night all the time, the sun had been taken out of my day." (Tracey)

This super-ordinate theme captures the various strategies used by the mothers to disconnect from their emotions and the various functions that this seemed to serve. Minimising the circumstances around their children being taken into care seemed to allow mothers to create a narrative that could be lived with. The alternative to minimisation appeared to be an acceptance of the full reality of the situation which meant allowing themselves to know the mistakes that they had made. For the majority, there were moments when it was clear that they were acutely aware of these mistakes, and at others they were not. There was a sense of the mothers both connecting with and disconnecting from emotion. The other way in which disconnecting from emotion appeared to manifest itself in the mothers accounts was in the way they described coping with their emotions after their children were taken. All of the mothers described coping by blocking out or numbing their emotions at that time. This seemed in part due to the intensity of the emotions and in part due to their sense of shame which left many feeling they had no one to turn to.

\section{Renegotiating identity}

This theme captures the impact on the participants' sense of identity as a mother and as a person after their children were taken into care. All seemed to find themselves questioning who they were following separation from their children and questioning the sense that they had of themselves as 'good mothers'. For many, this loss of their sense of themselves led to feeling that their lives had lost meaning and for some it felt as though life was not worth living. Often they expressed the need to move on with their lives and take on a new role but also the need or wish to improve themselves somehow.

Their accounts suggest that this renegotiation is continuous and without resolution. It highlights the confusion evoked for the mothers which in part is about an internal struggle to reconcile being a mother and not a parent. It also, though, reflects the struggle to name this 'in-between' state in a society which offers no validation or guidance for this position.

Tracey had a strong identity as a mother from a young age and her life continued to centre around her children after they were taken. She describes feeling like a mother when with her children, but not feeling like a mother when she is apart from them which left her feeling confused about her sense of herself:

"I understand that I'm always gonna be their parent... mother, but having them not in my life is.... Especially the two that are up for adoption, not having them in my life but knowing they're out there and they're being raised by someone else. I see myself as a part-time mum. When I've got contact with them, that's when I'm a mum, but other than that I'm just me now. And I'm just trying 
to work out who me is. All I've known from the age of 17 upwards is being a parent. Erm, so, to have them suddenly removed... I just didn't know who I was anymore. And I couldn't work out who I was." (Tracey)

Kate questions her identity as a mother in the context of what other people might think. She expresses something important about whether or not she is a mother and a parent in the eyes of others:

"Am I still a parent? Sometimes I ask myself that. Yes, of course I'm still a parent and I'll always be her mum, but I do get questions. People that don't know the situation are like, 'have you got any children?' Sometimes I choose to say no, I don't have any children because then I don't have to go into details and other times, if I feels it's somebody that I maybe, possibly could trust, I will." (Kate)

As Kate goes on, she alludes to feeling that she would be a different person had she not made the decision to change her life; a decision which was triggered by her child being taken into care:

"If hadn't of got into the further education or finding a career then god knows where I'd be. I'd probably be on the streets begging for money, taking drugs and stuff like that. Only I could make that decision that I wanted to change my life and I knew that." (Kate)

Tracey described a wish to be a different person to who she was when her children were taken, alluding to the need to move away from her 'old self' which she did not feel was 'okay' any longer:

"Don't be the same person that you was when you had your children taken." (Tracey)

This theme represents the mothers' need to 'better themselves' or transform themselves somehow in an attempt to reduce their sense of shame. For the majority of participants, it seemed that, even after many years, they were still in a process of grappling with their sense of themselves. Having their children taken into care was a shock to them all and seemed incongruent with their own hopes and expectations as a mother. As a result, many of the mothers felt a strong need to find a new identity or to repair their identity in some way.

\section{The children are gone but still here}

This theme represents the challenges for the mothers of being in an 'in-between state' in which they have lost their children, but continue to have contact with them. Contact evoked complex feelings for mothers who were, in parallel, processing painful feelings in relation to their loss and sense of identity. In many ways, contact was viewed as very precious. It provided a way for the mothers to try to hold onto a parenting role as they tried to have some influence over their children's upbringing. It also meant that mothers were able to have information about their children which allowed them to have a relationship with them even when they were not together. However, having contact with the children that they had lost also brought with it challenges. Despite the mothers looking forward to contact, they also felt a pressure and anxiety to make it special and memorable. This seemed to be as a result of the infrequency with which they saw their children and also a result of their sense of guilt for the situation their children were in. The infrequency of contact also left the mothers with a sense of the children being like strangers to them, which again created uncertainty and anxiety at the time of contact. Having contact meant that, while mothers were able to say 'hello' to their children, inevitably then came the need to say 'goodbye'. For those who had regular direct contact, this was very painful. Saying goodbye both immersed them in the reality of the situation which was that their child was being parented by somebody else, and also reignited feelings of guilt and anger towards themselves. 
Lucy expresses the pressure she feels and associated anxiety to make the time they have together special, describing herself as 'over-run with emotion' at these times:

“... You're so over-run with all these emotions of 'oh my god, I'm not going to get to take them to the cinema ever, I'm not going to do...' So them things become more important to get done and it becomes... they're enjoyable, but there's always... there's this other bit where you're thinking... anxiety... oh what can we do to make it special.... especially when it's their birthday or Christmas. It all has different elements to it I think." (Lucy)

Eve captures her mixed feelings about contact well when she says:

"I can't wait to see her, but I'm dreading it. I don't know how she's going to be, how she's going to be towards me. I don't know if she's going to be angry, happy and sad; I don't know what's going to happen... I don't know the children. I don't know what they like, what they don't like." (Eve)

Alice expresses the importance of having information about her child as a way for her to still feel like a part of his life. She alludes to the idea that having information about him allows her to maintain a relationship with him even though they are apart:

"I get photos, so I get to see how he's growing up and they put a lot of detail in it... what he's into, how he's doing at school, what he's been doing with his friends... which is really nice cos then it feels like I'm still... I'm still part of his life. And then, if and when he decides to come back, we haven't gotta start from scratch, it'll be like we already know each other." (Alice)

For Tracey, saying goodbye reminded her of the mistakes that she made which led to her children being taken into care. Each time she saw the children upset at saying goodbye, she experience both guilt and anger at herself:

"Saying goodbye, that's the challenge... I still find it hard, but I seem to find it more hard with the girls but then that's because they always cry when it's goodbye time, so that always puts the extra, you know, if I hadn't messed up, we wouldn't be having to say goodbye, therefore they wouldn't be crying now. So that's sort of like brings the guilt back n everything else, and I get angry at myself for messing up and for putting my kids through pain." (Tracey)

This super-ordinate theme represents the complex emotions that contact evokes for mothers who are, in parallel, trying to renegotiate their identities as mothers and parents, and to process the loss of their children. Contact seemed to help the mothers with their sense of grief at the loss of their children because they were able to feel a part of their lives. However, it also served to highlight their loss, particularly in having to say goodbye and seeing the distress of their children.

\section{Discussion}

\section{Trauma}

The super-ordinate theme 'disconnecting from emotion' speaks to the way in which the mothers' accounts lacked emotional content. It also represents the overwhelming nature of their feelings in relation to their loss and the ways in which they attempted to cope with these. These findings are consistent with research that views the removal of children into care through a trauma lens (Castle, 2010; O'Leary-Wiley \& Baden, 2005; Charlton et al, 1998; Wells, 1993). 
All the mothers described intense shock and disbelief after their children were removed. All recalled vividly the moment that their children were taken and, in particular, the distress of their children. All described coping through avoidance of their emotions, of people and places that reminded them of their children, and of friends and family. The accounts of the mothers and their disconnection from emotion can be seen as consistent with the concept of 'psychic numbing', defined by Litz, Schlenger, Weathers, Caddell, Fairbank, \& LaVange, (1997) as a loss of interest, detachment from others, and lack of emotional responsiveness.

\section{Disenfranchised grief}

The super-ordinate theme 'No one in my corner' speaks to the accounts of the majority of mothers who talked about feeling that they were left to cope alone after their children were taken into care. There was a strong sense that they felt their grief and their loss was not considered to be legitimate. This was also evident in accounts such as 'I should be happy now that my children are happy' and 'my feelings don't matter, it's all about the children'. The majority of mothers described or alluded to not feeling like a person who has needs and feelings in relation to their children being taken into care. This finding speaks to the strong social discourses around motherhood which create a stigma for mothers whose children have been taken into care.

Mather \& Rutherford (1996) suggest that socially acceptable behaviour enables individuals to gain social reinforcement and acceptance. It is likely to follow, then, that expressing emotions in relation to having one's children taken into care puts one at risk of being excluded from a social group. This can be viewed as consistent with the concept of disenfranchised grief (Doka, 1989) which suggests that stigma influences the process of grieving and psychological adjustment to loss. Doka (1989) suggests that disenfranchised grief occurs when a loss is not acknowledged or socially validated. It is a concept that is particularly relevant to what Boss (1999) calls 'ambiguous losses', of which having a child taken into care or adopted is one. She identifies two types of ambiguous loss, the most relevant being when a person is physically absent yet psychologically present and suggests that having a child taken into care or adopted is an example of this. It is a loss which, unlike death, is undefined, not immediately recognizable to others and does not have rituals around it such as a funeral. When someone dies, there are cultural practices and social support systems which help to facilitate the grieving process because loss through death is publicly recognised and legitimized (Robinson, 2002; Betz \& Thorngren, 2006). As a result one is more likely to receive support from the community. Disenfranchised grief is a concept which Aloi (2009) has linked to the experiences of mothers who voluntarily relinquished their child for adoption and one which appears equally relevant, if not more so, for mothers whose child has been compulsorily removed.

\section{Experiences of the child protection process}

The sub-theme 'one story obscuring other stories' represents a feeling described, or alluded to, by the majority of mothers that evidence for the court was presented in a way which painted a narrow picture of them as parents. In addition, many felt extremely frustrated and powerless in the face of a confusing and adversarial court process. This is consistent with the findings of other studies which discuss the impact of an adversarial court process (Ryburn, 1994; Cleaver \& Freeman, 1995; Mason \& Selman, 1997; Drumbill, 2006; Ghaffar et al, 2011; Smeeton \& Boxall, 2011). In Smeeton \& Boxall's (2011) study of mothers' perceptions of the child protection process, they too found that mothers' felt as though they had lost ownership of their stories which had been re-written for them by professionals.

\section{Managing 'spoiled' identities}


The accounts of the mothers suggested that they found themselves renegotiating their identity after their children were taken into care. In particular, their accounts represented a strong need to move away from the stigma that surrounded them and from an identity of a 'bad' or 'failed' parent. For some this meant that they tried to 'better' themselves by, for example, finding a new career, moving away and getting out of destructive relationships, represented by the theme 'Repairing myself'. This theme speaks to Goffman's (1963) concept of 'spoiled identities' which he coined in his book 'Stigma - Notes on the Management of Spoiled Identity'. Holt (2010) defines the concept well in saying that it is 'an identity which possesses an 'undesired differentness' and which therefore needs to be carefully managed' (p. 416). This 'management' of identity appears consistent with the findings of this study which saw the mothers in a continuous process of trying to renegotiate and redefine their identities.

Another way in which the mothers in this study tried to defend against a 'bad mother' label was to create a narrative for themselves that could be lived with (Schofield et al, 2011), and one which they could present to others. This was illustrated in their minimisation of the circumstances around which the children were removed. There were moments for many of the mothers where they showed an acceptance of their mistakes, but this was painful to stay with. As a result, many seemed to find it easier to be with a narrative in which services and professionals were to blame as it allowed them to defend against the alternative which threatened their identity and selfesteem.

\section{The complexity of contact}

Betz \& Thorngren (2006) suggest that following the ambiguous loss some may no longer know what their role entails. Furthermore, they suggest that mothers whose children have been taken away may feel confused as to whether or not they are a mother at all if they are not raising their child. This is consistent with the finding of the current study. Some described trying to parent their children during contact but finding themselves in a 'tug of war' with the foster carers or adoptive parents who were raising them with values of their own. Neil (2003) suggests that the role of birth relative, particularly after adoption, is poorly defined, raising further questions for them in terms of their identity. This is consistent with the findings of the current study in which some of the mothers talked about not knowing what to say, how to behave and, in general, not really knowing what the 'rules' around contact were.

Although contact meant that the mothers were able to see their children (for those who had faceto-face contact), it also meant that they continually had to say 'goodbye' to them. Many described the pain of seeing their children distressed at saying goodbye which reignited feelings of anger towards themselves because it served as a reminder of their own 'failings' as a parent. It also reignited feelings of grief at their loss. In her thesis exploring the experiences of mothers who voluntarily relinquished their child for adoption, Castle (2010) writes:

'Contact between a birthmother and her relinquished child is perceived as a (partial) solution to a painful decision, a salve to an enormous loss. For some it meant not having to say goodbye. Yet it is a solution that also appears resistant to fully resolving the grief associated with the act of relinquishment.' (p. 243)

\section{Experiences of support}

The theme 'I was on my own' represented the feeling from the majority of mothers that, if they had been given the right support, their children may not have needed to be taken into care. Some talked about feeling that they needed therapy at the time in order to be able to manage their own emotional difficulties but that it was not in the timeframes for their children for them to undertake this. Others felt that professionals had been aware of their difficulties with parenting 
their children, in the context of a chaotic situation at home, for a long time but that support was not put in place to help them with this.

Alpert (2005) suggests that services are not always available to parents in a timely and accessible manner. Although Alpert's (2005) study is an American one, it raises many of the issues that exist in UK services. For example, she raises the point that many parents are mandated to attend therapy as part of proving fitness to parent but that the services that provide this are often unavailable or inaccessible.

Access to support services is perhaps particularly important for mothers whose children have been taken away because many are isolated in the sense that they have poor family and community support networks, as was one of the findings of the current study. This was also found by O'Neill (2003) who suggests that not only is this likely to have contributed to the reasons why their children were removed, but would almost certainly contribute to the mothers' subsequent ability to cope.

\section{Significance of their own backgrounds}

Although not asked about in the interview, many of the mothers described or alluded to having come to motherhood with their own histories of trauma, abandonment and loss. One of the mothers had herself been adopted.

One of the themes that one could consider in the context of the mothers' backgrounds is that of minimising seriousness. As discussed, while this theme could represent a wish to disconnect from emotion and to create a narrative that can be lived with, viewed through an attachment lens, it could also reflect a reduced capacity to understand the impact that their actions were having upon the emotional development of their children.

Many of the mothers in this study described childhoods in which they were physically abused or neglected which might suggest that they were not able to develop secure attachments and therefore the ability to mentalize. One of the ways that the mothers demonstrated difficulty in understanding the impact of their actions on the children's emotional development and wellbeing was in their descriptions of ways in which their children were cared for physically. Some for example, talked about how the children 'had food in their tummies' and 'a roof over their head' as a way of demonstrating that the children were not neglected.

\section{Clinical implications}

\section{Early interventions}

The findings support the need for early intervention programmes to prevent the transmission of maternal trauma. Crucially though, this should form a part of an approach which addresses the complex needs of mothers and families in a holistic manner. The findings of the study suggest that clinical psychologists can, and should, play a key role in providing early and intensive interventions for at-risk and vulnerable mothers and their families. The findings fit with the recent government initiative called '1001 Critical Days' (DoH, 2013) which highlights the importance of intervening early in order to improve outcomes for children and their families. Specifically, it suggests that the period between conception and the age of two is a critical 'window of opportunity' in which the greatest change can be affected.

The importance of early intervention is already well-known and has a large evidence-base. The Parenting Early Intervention Programme (PEIP) was an initiative begun in 2008 to fund local authorities in England to deliver evidence-based parenting programmes. Outcomes of these 
programmes showed that there were substantial improvements in parents' emotional well-being, parenting styles and improvements in their children's behaviour as a result of attendance at parenting programmes (Allen, 2011). It seems crucial to provide intervention and support at an early stage to prevent a situation in which parents are struggling to parent and children are at risk.

\section{Holistic and comprehensive services}

While parenting interventions are important and have some impact on the parent-infant relationship they, crucially, do not address the wide ranging and complex difficulties that surround these parents. For example, Balbernie (2001) argues that poverty is a key risk factor which must be addressed as it impacts on all other risk factors associated with the care giverinfant relationship. Furthermore, in her report 'Listening to Troubled Families', Casey (2012) argues that families' difficulties are complex and she suggests that trying to 'fix' single issues such as 'drug-use' is 'destined to fail' (p. 64). Instead, Casey (2012) suggests that services should have an understanding of the family as a whole as well as what has happened to the parents as children. The social work model 'Reclaiming Social Work' (Goodman \& Trowler, 2012) was developed in response to children's services becoming risk-averse, anxious and over-bureaucratised, largely following tragic deaths such as that of Peter Connelly. It was first introduced in Hackney and resulted in a $40 \%$ reduction in the number of children being taken into care. The model, which radically transformed the process of child protection in the borough, aims to work proactively with families, privileging direct work with them in order to keep families together where possible. Embedded in this model are clinical practitioners, such as clinical psychologists, who work with the parents and the family as a whole. Here, clinical psychologists can play a key role in providing clinical interventions, at an early stage, to assess and work with the needs of both the parents and their children. This could be, for example, through a combination of individual therapy, as part of addressing the significance of their own backgrounds, and systemic therapy. In addition, clinical psychologists can, and should, make a significant contribution towards developing a culture of systemic and psychological thinking about child protection work through providing consultation and supervision to social work practitioners. This may help to keep families together through helping practitioners to develop risk formulations and in preventing reactive, risk-averse decision-making. It may also allow space for practitioners to reflect on their own feelings about the work and their relationship with empathy in working with these families.

As part of providing holistic and comprehensive services, it is important to consider the impact of, and response to, mothers' experiences of the child protection process. The findings of this study suggest that mothers experienced the process as both adversarial and 'all-powerful', leaving them feeling disempowered and marginalised. While it is acknowledged that the power imbalance is very often necessary in child protection, it is important for practitioners to be aware of, and be able to have conversations about, it's impact on parents. Featherstone \& Fraser (2012) piloted a parental advocacy scheme in England for parents whose children were subject to child protection proceedings. They call for 'a more robust recognition of how daunted parents often are by current systems' (p. 3) in policy and in practice. Of the eighteen parents surveyed in the study to evaluate the scheme, thirteen described the advocate as 'helpful' and felt they had facilitated their understanding of the process and represented their needs and views. Eleven felt that advocacy support had made it easier to communicate with the local authority and six believed it had helped them to contain their emotions, to feel empowered and to understand their rights. These findings require further consideration and are of high relevance to the findings of the current study in which the mothers often found the court process, at best, confusing and, at worst, impenetrable, particularly given the distress they were experiencing in parallel. Featherstone \& Fraser (2012) argue that: 
professionals and work in partnership and this needs urgent acknowledgement.' (p. 26)

\section{Post-proceedings services for parents}

Despite the fact that policies like the Adoption and Children Act (2002) have raised the profile of birth mothers and specify the need for post-adoption services, in practice this is minimal and does not mandate agencies to address their needs (Broadhurst \& Mason, 2013). Without specialist provision of support for mothers after their children have been taken into care or adopted, they are left to access mainstream services which is often not possible due to the high threshold for service eligibility. In many cases it would also mean a long waiting time. The findings of the current study, and the wider literature, indicates the need for support to be routinely offered to birth mothers to address their needs, and that this is currently not happening (Slettebø, 2013). As this study has shown, mothers whose children have been taken into care or adopted are a vulnerable group, many of whom experience mental health difficulties, socio-economic deprivation and bring with them the legacy of their own difficult and traumatic histories. The compulsory removal of their children serves to further their psychological distress. Given the pressures upon children's services, and the often ruptured relationship between these services and mothers, it seems important for independent support to be provided. Alongside a concern for the well-being of birth mothers lies a strong economic argument for providing interventions at an early stage. There is growing national concern about the successive removal of children to care or for adoption. Many parents find themselves in a cycle of recurrent legal proceedings which, as well as causing untold distress, costs the local authority approximately $£ 15,000$ per care proceeding (Broadhurst \& Mason, 2013). Research has shown consistently and unequivocally that birth mothers are a marginalised group with complex needs. It is argued that support for mothers following their children being taken into care should take the form of a multi-disciplinary approach so that their needs are addressed holistically. It is argued that clinical psychologists can, and should, play a key role. Broadhurst \& Mason (2013) support this view:

'We would argue that it is timely to consider a post-proceedings protocol for parents, which would encourage a proactive multi-agency approach to enable the cycle of repeat pregnancies and removals to be broken.' (p. 298)

In an American study, Kriebel \& Whitten (2014) surveyed training programs in clinical psychology and found that adoption information was severely underrepresented, with $65 \%$ of clinical psychologists unable to recall any teaching that addressed adoption. It seems important that the complex issues surrounding mothers whose children are in care or adopted are included. Since such a high number of these mothers experience mental health problems, it is likely that psychologists will be in contact with them and it is important that the possible impact upon them of the removal of their child or children is understood (Sass \& Henderson, 2002). Robinson (2002) describes post-adoption grief counselling for birth mothers as part of a government funded group called the Association Representing Mothers Separated from the Children by Adoption (ARMS), run in South Australia. Here they use a narrative-based approach, designed specifically for the client group. Given the finding of the current study that the mothers felt that services were de-contextualising their story, narrative approaches may be useful to enable them to re-author and take back ownership of their stories (White, 2007). This may serve to reduce feelings of shame and disenfranchised grief by allowing a richer story to be told which would include their love for their children, the positive moments they shared with their children and the parenting they were able to maintain despite the problems. This kind of intervention may also serve a dual purpose of supporting mothers to manage a 'spoiled identity' by eliciting other stories about themselves. Clinical psychologists are in a unique position to be able to deliver complex interventions such as these. 
A strong finding of the current study was the mothers' tendency to minimise the seriousness of their actions, or inactions, which led to their children being taken into care or adopted. This suggests that it may be important to address issues of responsibility before embarking on therapeutic work or to make this an integral part of the work. Working with these mothers to help them to hold more responsibility may also ameliorate their anger with services and make their voice more likely to be heard. In his book, 'Invitations to Responsibility', Jenkins (1990) describes narrative approaches he used with men who were violent and abusive. He suggests that 'the more forcefully we argue for responsibility, the more we invite the perpetrator to argue for the avoidance of responsibility' (Jenkins, 1991, p. 193). If conversations about the taking of responsibility leave mothers drawing negative conclusions about their identity, responsibility will be resisted. Instead, conversations with mothers which explore, for example, preferred relationships with their children are more likely to allow for safe exploration of their current or past relationship and, importantly, the chance for redemptive action. Interventions in a group format are also likely to be a useful way in which to begin to have conversations about responsibility. For example, these conversations could be integrated into mentalization-based group therapy programmes (Bateman \& Fonagy, 2004) which, in and of themselves, may contribute towards accepting responsibility through the development of empathy. If mothers are able to develop their capacity to mentalize and to understand the impact of their actions, and inactions, upon their children they are more likely to be able to hold responsibility. For some of the mothers in the current study, it appeared that their difficulty with mentalizing contributed to the externalisation of responsibility, for example, through blaming services and professionals.

\section{Conclusions}

The findings of the current study, and of others, suggest that the experiences of birth mothers are complex. They face psychological tasks such as processing complex and disenfranchised grief, coping with difficult feelings such as guilt and shame, and renegotiating identity in the context of stigma. In parallel they are, more and more commonly, faced with the task of sustaining useful contact with their children and maintaining effective relationships with foster carers or adoptive parents.

Clinical psychology has much to offer in understanding the experiences of birth mothers whose child has been taken into care or adopted. Clinical psychologists are trained to understand and formulate highly complex difficulties drawing on a range of psychological theory. In particular they are trained to work across the lifespan, focussing on understanding developmental tasks, adjustment to life transitions and healthy coping skills. Importantly, clinical psychology is concerned not just with the individual but with systemic ideas which consider the influence of social and cultural issues upon individuals. The findings of the current study suggest the importance of thinking systemically when considering the experiences of mothers. Given the complexity of the birth mother experience, it seems vital that clinicians working with them are aware of and sensitive to the issues and dilemmas that they face. Furthermore, clinical psychologists as scientist-practitioners are in an excellent position to contribute to both research and clinical practice in the field of child protection. 